\title{
Letramento de Meninas em Programação através do Pensamento Computacional para Compreensão de Problemas
}

\author{
Vânia . Marquiori'1, Márcia G. de Oliveira', Gabriel da S. Nascimento² \\ ${ }^{1}$ Instituto Federal do Espírito Santo \\ 2Instituto Federal de São Paulo \\ (marquiori@ifes.edu.br; clickmarcia@gmail.com, tilgabriel@gmail.com)
}

\begin{abstract}
This paper deals with the retraction of women in the career of computer science and the difficulties of understanding and its implications in the process of training programmers. In this way the work proposes the offer of workshops based on the pillars of computational thinking for girls from the fifth to ninth grade of elementary school in public school. The proposal is the result of an experience of initiation to programming with a deaf student, and aims to develop literacy in programming through computational thinking to understand the problems arousing the interest of girls in the area.
\end{abstract}

Resumo. Este trabalho trata da retração das mulheres na carreira da ciência da computação e das dificuldades de compreensão e de suas implicações no processo de formação de programadores. Desta forma o trabalho propõe a oferta de oficinas baseadas nos pilares do pensamento computacional para meninas do quinto ao nono ano do ensino fundamental em escola pública. A proposta é resultante de uma experiência de iniciação à programação com uma estudante surda, e tem como objetivo desenvolver o letramento em programação através do pensamento computacional para compreensão dos problemas despertando o interesse de meninas pela área.

\section{Introdução}

No decorrer da história, a tecnologia tem permeado cada vez mais a vida humana, apresentando contribuições na resolução de diversos problemas, através do desenvolvimento de ferramentas, dispositivos e aplicativos. Para resolver necessidades humanas através de soluções tecnológicas, fazem-se necessárias melhorias na formação de profissionais, para que sejam capazes de propor soluções efetivas para os problemas.

Para a resolução de problemas, a Ciência da Computação utiliza um método conhecido como pensamento computacional que é "uma forma para seres humanos resolverem problemas”[Wing 2016]. No entanto, a formação em Ciência da Computação apresenta altos índices de evasão, e a maioria dos fatores que desviam os iniciantes da carreira relacionam-se às deficiências em conhecimentos básicos (Paula, Piva Jr e Freitas 2009), e não propriamente aos conteúdos de programação[Delgado et al. 2005].

A evasão na área é maior quando se trata das mulheres [Nunes 2016], pois elas enfrentam, além desses problemas, aqueles relacionados à desigualdade de gênero, pois a área é majoritariamente masculina [Lima 2013]. Assim, propõe-se neste trabalho desenvolver o letramento em programação com meninas, por meio de oficinas desplugadas que trabalhem os pilares do pensamento computacional. O letramento digital de acordo com Soares [2002] é o estado em que se encontram os sujeitos que se 
apropriam da tecnologia e exercem neste ambiente suas práticas de leitura e escrita, de forma que "os processos cognitivos inerentes a esse letramento digital reaproximam o ser humano de seus esquemas mentais” [Soares 2002].

A proposta dessas oficinas tomou forma a partir de uma experiência de iniciação à programação de uma estudante surda em uma perspectiva de desenvolvimento das habilidades de compreensão e sequenciação lógica. Considerando as dificuldades da aluna surda em compreender as instruções de programação, foram desenvolvidas atividades de compreensão de enunciados de problemas identificando entradas, processamento e saídas e de criação de sequências lógicas para resolver esses problemas.

A contribuição deste trabalho guarda relação com a Educação Profissional, pois sua proposta poderá contribuir com a diminuição da desigualdade de gênero na Ciência da Computação, ao trabalhar com meninas das séries finais do ensino fundamental, com oficinas que desenvolvam habilidades e possam despertar o interesse destas pela área.

O trabalho encontra-se organizado da seguinte maneira: na segunda seção apresentam-se a revisão de literatura e trabalhos relacionados ao tema. Na terceira seção encontra-se a programação metodológica das oficinas. Na quarta seção encontram-se expostos os resultados esperados. Na quinta seção, apresentam-se as considerações finais.

\section{Revisão de literatura}

A tecnologia, assim como outros acontecimentos, têm provocado mudanças no mundo do trabalho. Uma dessas mudanças foi a conquista de espaço pelas mulheres, que embora represente uma vitória para o universo feminino, ainda apresenta predominância masculina quando se trata do desenvolvimento de atividades automatizadas, resultando em maior exploração da força de trabalho feminino [Antunes 2009]. Essa segregação de gênero na área tecnológica acontece desde a escolha da carreira, como é o caso da Ciência da Computação[Nunes 2015 e Lima 2013].

No entanto, a história mostra que a primeira pessoa a receber o título de programadora, foi uma mulher, Ada Byron - Lady Lovelace [Toole 1998], servindo para contrapor a ideia de que a programação é uma profissão masculina.

O desenvolvimento tecnológico tem dominando o universo do mundo do trabalho, e a escola deve acompanhar essa perspectiva buscando generalizar as tecnologias. No entanto, as escolas têm encontrado resistências nas relações sociais [Saviani et al. 1994], mostrando que a linguagem de programação ainda é um privilégio das classes dominantes [Lima 2013]. Isso porque a sociedade atual necessita de pessoas capazes de adaptarem-se aos novos requisitos como a autonomia intelectual e à resolução de problemas [Brasil 2012], cada vez mais presentes no mundo do trabalho.

Dos entraves que afetam o ensino de programação, muitos se associam à falta de conhecimentos prévios em disciplinas básicas, gerando a falta de compreensão de problemas de programação, afetando diretamente os ingressantes na área [Paula, Piva Jr e Freitas 2009 e Delgado et al. 2005]. E o sucesso da compreensão depende do grau de interação que o leitor consegue estabelecer com o texto, podendo este exigir mais ou menos conhecimento do leitor para ser compreendido [Koch e Elias 2008]. Admitindo-se a complexidade da linguagem de programação, considerando a combinação de várias 
habilidades cognitivas para sua aprendizagem [Oliveira et al. 2015], antes de programar, o sujeito do processo precisa se familiarizar com o código.

\subsection{Trabalhos relacionados}

Buscando relacionar o presente trabalho, que tem como objetivo a utilização de oficinas baseadas nos pilares do pensamento computacional como ferramenta para auxiliar as alunas na resolução dos problemas propostos, destacam-se os seguintes trabalhos: o de Medeiros et al [2018], que trata da utilização da poesia compilada com objetivo de facilitar o processo de ensino-aprendizagem de algoritmos através da associação de uma estratégia que já faz parte do cotidiano das pessoas.

Para as autoras, a utilização da poesia compilada para o ensino de programação através do desenvolvimento do pensamento computacional pode ser concebida resumidamente no ensino da linguagem de programação através da união das características desse gênero textual, com as da programação. Outra experiência das autoras mostra o ensino de programação através da Poesia Compilada, em uma escola pública de ensino fundamental, que obteve sucesso através da computação desplugada.

Os trabalhos de Queiroz e Santos [2018] discutem a aplicabilidade da linguagem de programação para o desenvolvimento do pensamento computacional têm permeado a Educação Básica, precisamente no Ensino Fundamental II, de forma interdisciplinar. Essas pesquisas corroboram com a proposta, pois aliar outras áreas ao ensino de programação é uma via de mão dupla, pois o pensamento computacional passa a ser utilizado nas disciplinas, sendo trabalhado cotidianamente [Queiroz e Santos 2018].

\section{Metodologia}

A proposta das oficinas consiste em observar o desenvolvimento de meninas que estejam cursando regularmente entre o quinto e o nono ano do Ensino Fundamental de uma escola pública do município de Nova Venécia-ES, através de oficinas de programação vinculadas ao Projeto Corte de Lovelace, projeto parceiro do Programa Meninas Digitais da Sociedade Brasileira de Computação (SBC) ${ }^{1}$.

As atividades das oficinas serão baseadas em metodologias ativas, mais especificamente a abordagem de Aprendizagem Baseada em Problemas, definida por Filatro [2018 p. 32] como "uma abordagem que utiliza situações problema como ponto de partida para a construção de novos conhecimentos”, e trabalharão as habilidades de compreensão a partir dos próprios conteúdos de programação [Antunes 2001].

$\mathrm{Na}$ metodologia de ensino de programação para alunas surdas, foram utilizadas diversas oficinas, entre elas uma que abordava compreensão através de problemas reais. Tendo sido uma ferramenta que apresentou aprendizagem significativa, a ideia consiste em adaptar a ferramenta para utilização no Ensino Fundamental, com problemas que possam despertar o interesse das meninas, de acordo com a seguinte programação:

\begin{tabular}{|l|l|l|}
\hline Oficina & Carga horária & Objetivos \\
\hline $\begin{array}{l}\text { Primeira } \\
\text { oficina } \\
\text { Confeitaria }\end{array}$ & 2 horas & $\begin{array}{l}\text { Propor a escrita de algoritmo de fazer e outro de confeitar um bolo. E também uma atividade prática de confeitar o } \\
\text { bolo. Serão levados todos os materiais necessários para confeitar o bolo e o bolo já pronto para que as meninas } \\
\text { possam colocar em prática o algoritmo que escreveram. Ao final, será feita uma comparação entre o que escreveram o }\end{array}$ \\
\hline
\end{tabular}

${ }^{1}$ Meninas Digitais: $\underline{\text { http://meninas.sbc.org.br/. }}$ 


\begin{tabular}{|c|c|c|}
\hline & & $\begin{array}{l}\text { algoritmo inicialmente, com o que realmente seguiram e/ou modificaram para que o bolo chegasse ao resultado } \\
\text { esperado. }\end{array}$ \\
\hline $\begin{array}{l}\text { Segunda } \\
\text { oficina - } \\
\text { Maquiagem }\end{array}$ & 2 horas & $\begin{array}{l}\text { Nessa oficina a proposta será lançar um desafio para as alunas: como montar um tutorial de maquiagem similar aos } \\
\text { vistos no Youtube. Pretende-se dividir as alunas, entre três a quatro grupos, sendo o ideal de três pessoas por } \\
\text { grupo.Cada grupo deverá ser formado por uma pessoa responsável por fazer as anotações dos passos a serem } \\
\text { seguidos; outra pessoa responsável por conferir e seguir os passos anotados; e outra pessoa que será escolhida para } \\
\text { ser maquiada; } \\
\text { A ideia é ter um revezamento dentro dos grupos, para que todas que queiram, possam ser maquiadas pelas colegas, } \\
\text { que será uma motivação para participação. Os materiais serão levados para que as alunas possam efetivar a proposta. } \\
\text { A ideia é chegar ao final da oficina com um tutorial escrito dos passos a serem seguidos para fazer a maquiagem. Ao } \\
\text { final serão trabalhados os conceitos de entrada, processamento e saída, depois das meninas terem que utilizar as } \\
\text { habilidades de abstração, decomposição e escrita de algoritmo. }\end{array}$ \\
\hline $\begin{array}{l}\text { Terceira } \\
\text { oficina - } \\
\text { Maquete } \\
\text { caminho de } \\
\text { casa para } \\
\text { escola }\end{array}$ & 2 horas & $\begin{array}{l}\text { A proposta consiste em dividir as alunas em dois ou três grupos e eleger uma das colegas para realizar as seguintes } \\
\text { etapas: } \\
-\quad \text { Escrita do algoritmo de ir de casa até a escola; } \\
\text { - Mapear o caminho de casa até a escola através de uma maquete. } \\
\text { Inicialmente pretende-se dividir as alunas, entre dois ou três grupos, e o grupo deverá escolher uma das pessoas para } \\
\text { ser ceder o endereço para a construção do caminho de casa até a escola. Ao final da oficina, deseja-se que as alunas } \\
\text { tenham: } \\
\text { - Escrito o algoritmo de ida até a escola; } \\
\text { - Construído a maquete; } \\
\quad \text { Comparar o algoritmo com os passos para a construção da maquete, e como algoritmo interferiu na } \\
\text { construção da maquete. }\end{array}$ \\
\hline
\end{tabular}

A pesquisa será de cunho qualitativo, envolverá a solicitação da participação dos professores como facilitadores para a execução das oficinas durante suas aulas. Envolverá também a observação do desempenho através de análise das atividades realizadas.

\section{Resultados esperados}

A expectativa quanto aos resultados da pesquisa, partindo das premissas dos trabalhos relacionados, levam a crer que os ganhos serão mútuos, no sentido das oficinas, como atividade extra, contribuir para o desenvolvimento das atividades curriculares. Espera-se ainda disseminar a linguagem de programação através da valorização de problemas presentes no cotidiano das meninas, com a utilização do pensamento computacional.

\section{Conclusão}

Considerando a versatilidade do pensamento computacional que permite aplicação em diversos contextos, os trabalhos futuros a partir deste poderão ser propostas fundamentadas no pensamento computacional, objetivando desenvolver as diversas habilidades cognitivas requeridas para aprendizagem da programação, considerando que tais práticas poderão conduzir a resultados satisfatórios nas mais diversas áreas.

\section{Agradecimentos}

Agradecemos ao Instituto Autoglass pelo apoio concedido às meninas do projeto Corte de Lovelace para a apresentação deste trabalho e ao Mestrado ProfEpt do Ifes - Campus Vitória, pelo desenvolvimento dessa pesquisa.

\section{Referências}

ANTUNES, R. (2009). Os sentidos do trabalho: ensaio sobre a afirmação e a negação do trabalho. 2. ed. $10^{a}$ reimpressão. São Paulo: Boitempo.

ANTUNES, C. (2001). Trabalhando habilidades: construindo ideias. São Paulo:Scipione. Brasil. (2012). Ministério da Educação. Parecer Conselho Nacional de Educação Câmara de Educação Básica nº 11/2012. Diretrizes Curriculares Nacionais para a Educação 
Profissional Técnica de Nível Médio. Conselho Nacional de Educação. Câmara de Educação Básica.

Delgado, C., Xexeo, J. A. M., Souza, I. F., Rapkiewicz, C. E., \& Pereira Jr, J. (2005). Identificando competências associadas ao aprendizado de leitura e construção de algoritmos. In XIII Workshop sobre Educação em Computação.

FIlatro, A. (2018) Metodologias Inov-Ativas na educação presencial, a distância e corporativa. 1.ed. São Paulo: Saraiva Educação.

Koch, I. V.; Elias, V. M. (2008). Ler e compreender: os sentidos do texto. 2 ed. São Paulo: contexto.

Lima, M. P. (2013). As mulheres na Ciência da Computação. Estudos feministas.

Medeiros, S., Rabelo, H., Nunes, I., Garcia, T. C. M., Medeiros, F., de Souza Rabelo, D.

S., \& Medeiros, A. (2018, October). Ensino de algoritmos com poemas através do editor Poesia (): Relato de experiência. In Anais dos Workshops do Congresso Brasileiro de Informática na Educação (Vol. 7, No. 1, p. 341).

Medeiros, S., Rabelo, H., Garcia, T. C. M., Nunes, I., Medeiros, F., Medeiros, A., \& de Souza Rabelo, D. S. (2018, October). Ensino de algoritmos através de Poesia Compilada e Computação Desplugada: Relato de experiência com alunos de Ensino Fundamental. In Anais do Workshop de Informática na Escola (Vol. 24, No. 1, p. 381).

Nunes, D. J. (2015). Educação Superior em Computação, Estatísticas 2015. Sociedade Brasileira de Computação-SBC. Disponível em: < http://www. sbc. org. br/documentos-da-sbc/summary/133-estatisticas/1074-educacaosuperior-em-Computa ção-estatisticas-2015>. Acesso em 08 nov 2018.

Oliveira, M., Nogueira, M. D. A., \& Oliveira, E. (2015). Sistema de apoio à prática assistida de programação por execução em massa e análise de programas. In: CSBC 2015-Workshop de Educação em Informática (WEI).

Paula, L. D., Piva Jr, D., \& Freitas, R. L. (2009). A Importância da Leitura e da Abstração do Problema no processo de formação do raciocínio lógico-abstrato em alunos de Computação. In XVII Workshop sobre Educação em Computação-WEI.

Queiroz, P., \& Santos, H. (2017). Contribuições do PIBID Interdisciplinar de Licenciatura em Computação e Pedagogia na Escola. In Anais do Workshop de Informática na Escola (Vol. 23, No. 1, p. 500).

Saviani, D. (1994). O trabalho como princípio educativo frente às novas tecnologias. Novas tecnologias, trabalho e educação: um debate multidisciplinar. Petrópolis: Vozes, 147-164.

Soares, M. (2002). Novas práticas de leitura e escrita: letramento na cibercultura. Educação \& Sociedade, 23(81).

Toole, Betty Alexandra.(1998) Ada Lovelace Biography. Disponível em: $<$ http://www.well.com/user/adatoole/bio.htm>. Acesso em 14 mar 2019.

Wing, J. (2016). PENSAMENTO COMPUTACIONAL-Um conjunto de atitudes e habilidades que todos, não só cientistas da computação, ficaram ansiosos para aprender e usar. Revista Brasileira de Ensino de Ciência e Tecnologia. 